\title{
Escritórios-piloto como mediação para o ensino-pesquisa-extensão em cursos de arquitetura e urbanismo
}

Pilot offices as mediation for the teaching-research-extension in architecture and urban plan-

ning courses

Autores

Lucília Machado. Professora titular aposentada da Faculdade de Educação da UFMG e coordenadora do Programa de Pós-Graduação em Gestão Social, Educação e Desenvolvimento Local do Centro Universitário UNA.

E mail: Ismachado@uai.com.br

Monica Villela. Leciona Desenho Técnico e Desenho Auxiliado por Computador na Faculdade Pitágoras Sistema de Educação Superior, em Belo Horizonte, Minas Gerais.

E mail: monicamansovillela@gmail.com

Recebido em: 20/07/2016 Aprovado em: 18/09/2017

DOI: $10.12957 /$ interag.2017.2473

\section{Artigo}

Este ensaio resulta de investigação realizada para fins de conclusão de um mestrado. Ela discutiu fundamentos, princípios, objetivos e condições concernentes à proposta de implantação de escritórios-piloto em cursos de Arquitetura e Urbanismo. Para tanto, procedeu-se à revisão de literatura e à consulta a professores e alunos de cursos de Arquitetura e Urbanismo de duas instituições universitárias, uma pública e outra privada. Além de informar, este ensaio contém elementos persuasivos, tais como recomendações ou sugestões sobre a implantação de escritórios-piloto como aparatos pedagógicos de formação de arquitetos socialmente referenciados e de contribuição para o desenvolvimento local. Trata-se de texto expositivo, argumentativo e de orientação técnica, dirigido, especialmente, a profes-

\section{Abstract}

This article shows the result of research conducted for the purposes of completing the master's degree, which discussed fundamentals, principles, objectives and conditions concerning the proposal for implementing pilot offices in the courses of Architecture and Urban Planning. For such, we went on to review the bibliography and to consult teachers and students of Architecture and Urban Planning courses in two universities, a public and a private one. In addition to reporting, this article contains persuasive elements, such as recommendations or suggestions on the implementation of pilot offices as teaching apparatuses for the training of socially referenced architects and as contribution to local development. This is an expository, argumentative and technical guidance text, directed especially 
sores e alunos de cursos de Arquitetura e Urbanismo e a todos os que possam se interessar pelo tema ou que tenham prerrogativas de decisão a esse respeito.

Palavras-chave: Ensino-pesquisa-extensão. Escritório-piloto. Arquitetura e Urbanismo. Desenvolvimento local.

Área temática: Educação

Linha de extensão: Desenvolvimento Urbano; Metodologias e Estratégias de Ensino/Aprendizagem. to teachers and students of Architecture and Urban Planning courses and to all who may be interested in the subject or who have decision-making prerogatives in this regard.

Keywords: Teaching-research-extension. Pilot Office. Architecture and Urbanism. Local Development

\section{Introdução}

Este ensaio objetiva apresentar reflexões sobre a importância da implantação de escritórios-piloto em cursos de Arquitetura e Urbanismo como estratégia e metodologia de ensino-pesquisa-extensão. Ele traz, também, orientações técnicas para essa implantação. Concebidos como espaços de integração de atividades de ensino, pesquisa e extensão comprometidos com a melhoria da formação profissional dos estudantes, os escritórios-piloto são também um aparato pedagógico destinado a promover a inserção social da instituição universitária nos esforços do desenvolvimento local. Neste ensaio são, portanto, detalhados aspectos relacionados à estrutura, organização e funcionamento desse aparato pedagógico, propostas fundamentadas em revisão de literatura e pesquisa de campo, realizadas para fins de conclusão de dissertação de mestrado.

Ao longo da história do desenvolvimento da arquitetura, com exceção dos séculos XVIII e XIX, pois nesse período a construção era marcada pela separação entre o belo e o funcional, verifica-se a estreita relação entre tecnologia, funcionalidade e expressão plástica na construção, elementos inseparáveis e indispensáveis, um ao outro.

O curso de Arquitetura e Urbanismo assim como a atividade profissional do arquiteto apresentam um universo extenso e complexo de possibilidades de intervenções na realidade natural e social existente, necessitando dessa forma de sólidos conhecimentos plásticos, urbanísticos e do domínio de tecnologias socialmente referenciados. O desafio está em oferecer contribuição à sociedade por meio da formação de arquitetos socialmente inovadores e soluções comprometidas com o desenvolvimento local pautado em relações sociais justas e igualitárias.

É de primordial importância levar em conta essas necessidades sociais na elaboração de projetos político-pedagógicos de cursos de Arquitetura e Urbanismo, na definição de seus objetivos, do perfil do profissional a ser formado e da matriz curricular, assim como das suas estratégias pedagógicas e métodos de ensino-aprendi- 
zagem. É nesse contexto de preocupações que se insere a proposta de implantação e desenvolvimento de escritórios-piloto nesses cursos.

Atualmente, o ensino de Arquitetura tem proporcionado aos alunos muito pouco dessas oportunidades formativas. Muitos deles não percebem a necessidade de promover a contextualização dos conteúdos ensinados e aprendidos considerando situações concretas e reais. Aliás, a prática profissional tem sido um objetivo deixado para ser realizado depois que o aluno se forma ou em estágios ou locais fora da universidade, onde muitas vezes se desenvolvem atividades distantes dos ideais da formação crítica e ampliada do aluno.

Contudo, a formação dos profissionais arquitetos requer vínculo estreito com a realidade social, a crítica necessária de como o mercado de trabalho impõe certos valores, que o aluno encontre no seu processo formativo oportunidades para desenvolver sua prática profissional.

A pesquisa que ampara este ensaio sobre a implantação e desenvolvimento de escritórios-piloto em cursos de Arquitetura e Urbanismo foi realizada nos anos 2014 e 2015 em Belo Horizonte, Minas Gerais, Brasil. Seu projeto foi submetido à avaliação por um Comitê de Ética em Pesquisa e por ele aprovado, conforme Parecer no 682.303, de 10 de junho de 2014. Ela foi desenvolvida observando-se os princípios éticos expressos pela Declaração de Helsinki e contou exclusivamente com recursos financeiros próprios. A coleta de dados não esteve sujeita a conflitos de interesse de qualquer ordem, pois foi realizada em instituições universitárias diferentes das que as autoras se acham vinculadas. Por sua vez, os objetivos e finalidades da investigação não foram movidos por interesses políticos e/ou financeiros.

Este ensaio tem como objetivo geral recuperar as contribuições fundamentais trazidas pela pesquisa realizada e que foram utilizadas para a produção de um guia de implantação de escritório-piloto em cursos de Arquitetura e Urbanismo. São objetivos específicos deste ensaio: a) apresentar sinteticamente a discussão sobre objetivos e finalidades desse aparato pedagógico com relação à formação profissional socialmente referenciada e à sua contribuição para o desenvolvimento local; e b) discutir aspectos de estrutura e funcionamento de escritórios-piloto adequados à realização da integração entre o ensino, a pesquisa e a extensão.

O campo de aplicação dos conhecimentos produzidos pela pesquisa realizada corresponde ao âmbito do trabalho pedagógico de formação de arquitetos. Trata-se, especificamente, da criação de um aparato que viabilize, de forma simultânea e articulada, as três atividades acadêmicas de um curso superior: a) o processo de ensino-aprendizagem contextualizado e comprometido socialmente; b) a extensão universitária capaz de realizar atendimentos com qualidade à população; e c) a pesquisa comprometida com a produção de conhecimentos de relevância social para o desenvolvimento local e a formação ampla, sólida e crítica dos estudantes.

A proposta da criação de um guia de orientação à implantação de escritórios-piloto decorre dos propósitos da pesquisa realizada de oferecer subsídios sobre uma das formas mediante as quais cursos de Arquitetura e Urbanismo podem viabilizar intervenções comprometidas com o desenvolvimento humano, social, ambiental e econômico 
de comunidades de baixa renda e, ao mesmo tempo, oferecer uma formação diferenciada e propositiva aos seus alunos.

O acesso a novas tecnologias, principalmente as de informação e comunicação, tem proporcionado oportunidades para grande parte da população brasileira de conhecimento sobre condições de vida e de bem-estar, dentre as quais as habitacionais. Acrescente-se a isso a maior atenção das políticas governamentais dos últimos anos a essas necessidades, traduzida por significativos índices de desenvolvimento social se forem consideradas as estatísticas oficiais. Contudo, a realidade social ainda está muito aquém do desejável com relação aos padrões de vida, pois se observa que esse crescimento não é generalizado e um número expressivo da população brasileira ainda vive na miséria absoluta.

De frente com a realidade atual, considerando as dificuldades e os progressos conquistados pela sociedade brasileira, os cursos de Arquitetura e Urbanismo não podem se negligenciar fechando seus olhos para os desafios do desenvolvimento local. É importante registrar que a Lei no 11.888, de 24 de dezembro de 2008, assegura às famílias de baixa renda assistência técnica pública e gratuita para o projeto e a construção de habitação de interesse social. Trata-se do cumprimento do que a Constituição Federal de 1988 determina em seu art. 6으, referente ao direito social à moradia. O inciso III do art. 4ำ da Lei no 11.888/08 estabelece que "profissionais inscritos em programas de residência acadêmica em arquitetura, urbanismo ou engenharia ou em programas de extensão universitária, por meio de escritórios-modelos ou escritórios públicos com atuação na área" poderão prestar "os serviços de assistência técnica objeto de convênio ou termo de parceria com a União, Estado, Distrito Federal ou Município".

O guia que foi produzido com base nos resultados da pesquisa realizada se apresenta, portanto, relevante no sentido de resgatar a ideia de escritório-piloto dentro de uma concepção inovadora do ponto de vista social.

Considerando que tem ocorrido grande expansão numérica de cursos de arquitetura no país, é importante contar com uma ferramenta, tal como propõe ser o guia, para reunir e prover informações sobre o conceito de escritório-piloto como aparato pedagógico e de inserção social dos cursos, facilitando-lhes a compreensão sobre suas possibilidades.

O guia vem, portanto, com o sentido de incentivar o desenvolvimento de propostas pedagógicas inovadoras, que contribuam de fato para o exercício crítico, criativo e responsável da profissão de arquiteto, o que significa atender também as demandas sociais do país.

\section{Sobre a pesquisa realizada, que fundamenta o Guia}

Além da revisão da literatura, mediante a qual foram exploradas as contribuições de cinco dissertações de mestrado e cinco teses de doutorado, que investigaram a formação profissional de arquitetos, realizou-se também um survey junto a alunos e professores de dois cursos de Arquitetura e Urbanismo. Em ambos os momentos investigativos, 
o propósito consistiu da produção de conhecimentos para fins de aplicação prática. Ou seja, reunir informações e sistematizá-las visando a oferecer uma contribuição técnica sobre como realizar a implantação de escritório-piloto.

O survey contemplou a aplicação de questionários a 20 professores, 10 de uma instituição pública e 10 de uma instituição privada. Incluiu também questionários dirigidos a 70 alunos, 35 de cada uma dessas instituiç̃ões.

A pesquisa realizada baseou-se em fundamentos teóricos, cujo resgate é de fundamental importância para a utilização do guia de orientação técnica sobre implantação de escritórios-piloto. Esses fundamentos tratam de questões sobre a necessidade do estreitamento da relação entre educação/escola com o contexto social; da promoção de encontros entre o que os estudantes estudam e as necessidades sociais; a superação das dificuldades da escola para ir além dos seus muros; as práticas pedagógicas inovadoras no ensino da Arquitetura e Urbanismo; o enriquecimento dos recursos pedagógicos para o ensino da Arquitetura e Urbanismo; a aplicação do princípio educativo da atividade no ensino da Arquitetura e Urbanismo e sobre a criação de estratégias para fazer a inserção do ensino da Arquitetura e Urbanismo na prática social.

A importância do estreitamento da relação entre educação/escola e contexto social para a formação de arquitetos urbanistas parte do pressuposto de que não é suficiente, no processo de ensino-aprendizagem, a tomada de conhecimento por parte do aluno de certo conteúdo, pois é preciso que ele o incorpore efetivamente por meio de uma atividade prática. Diz uma autora pesquisada:

Naquele momento a pesquisa mostrou a necessidade de se perceber a avaliação do projeto arquitetônico como prática social que não tem um fim em si, mas como engrenagem das práticas pedagógicas em arquitetura e urbanismo, num contexto sistêmico. Apontou que os processos avaliativos dos projetos expõem mais do que o grau de conhecimentos e habilidades acumuladas pelo aluno, contribuindo para explicitar os pressupostos que orientam as ações docentes e as expectativas institucionais. Ainda, para além de suas funções somativa e normativa, que mensuram resultados para a gestão dos fluxos acadêmicos, ficou claro o seu potencial formativo, pelo que podem fomentar o aprendizado.

A bagagem de conteúdos ministrada em cursos de Arquitetura é muito grande e a função dos professores não se reduz à informação simples e mecânica dos assuntos tratados. O gerenciamento desses conteúdos e sua aplicabilidade frente aos desafios da vivência profissional diária é o que se espera dos profissionais formados. Por isso, é fundamental que os cursos de Arquitetura e Urbanismo promovam os encontros entre o que os alunos estudam e as necessidades sociais.

O Conselho de Arquitetura e Urbanismo - CAU apresenta uma série de pré-requisitos inerentes ao profissional de arquitetura, considerando a necessidade de se assegurar a formação de caráter generalista. A Associação Brasileira de Ensino de Arquitetura - ABEA também propõe que o profissional em arquitetura tenha formação generalista, para que ele possa ter condições de intervir na realidade socioeconômica e cultural no que concerne às necessidades de toda a população. Ela também ressalta a importância de conhecimentos específicos, capazes de lhe conferir a capacidade necessária para 
enfrentar a complexidade inerente ao seu trabalho, tais como os referentes ao urbanismo, à edificação, ao paisagismo, à conservação e valorização do patrimônio construído, à proteção do equilíbrio do ambiente natural e à utilização racional dos recursos disponíveis. Um terceiro grupo de conhecimentos necessários se refere à intervenção do profissional no projeto arquitetônico e no espaço urbano com perspectiva inovadora e sustentável e, para tanto, embasada em valores éticos, sociais e ambientais. O quarto grupo compreende os conhecimentos necessários à elaboração de análises de dinâmicas urbanas e de transformações e melhorias dos espaços, o que inclui temas sobre formas de organização social e qualidade das edificações. Por último, mas não menos importante, é preciso que o profissional tenha na sua formação conhecimentos relacionados à demanda por projetos arquitetônicos e ambientação de interiores.

Pavesi aponta, ainda, a necessidade de superação do distanciamento entre prática e teoria na formação e atividade dos docentes desses cursos:

\footnotetext{
Com relação à qualidade das práticas educativas e à formação de docentes, os respondentes reivindicam a superação da divergência entre competências técnicas e pedagógicas, entre a teoria e a prática educativa, como condição para a efetividade dessa última, o que viria a corroborar os argumentos de Moraes (1990) e Loureiro (2004) quanto à inseparabilidade das duas dimensões. Para os autores, de fato, qualquer abordagem metodológica, pedagógica ou didática deveria ser presidida por considerações conceituais, filosóficas e, sobretudo, éticas, que resultem de uma reflexão sobre os desdobramentos sociais da prática educativa e permitam seu controle e aprimoramento, bem como o controle dos resultados sociais da atividade docente.
}

Schrega relata que a maneira de aprender se faz na medida em que se busca aplicar os conhecimentos adquiridos em situações reais. Dessa forma, se aperfeiçoam a sensibilidade e a percepção, possibilitando o amadurecimento do saber e, por que não dizer, da própria percepção do quanto já se sabe.

A busca no ensino muitas vezes se assemelha à busca da "pedra filosofal". O aprendizado baseado em problema (Problem Based Learning) ou aprendizado baseado em produto (Product Based Learning) são alguns dos muitos caminhos no ensino da arquitetura que procuram sensibilizar, despertar a percepção, abrir as portas do conhecimento contido ao redor, ao alcance dos olhos de cada um de nós.

O adequado gerenciamento de toda a bagagem de conteúdos ministrados, adquiridos e desenvolvidos pelos alunos não pode prescindir, portanto, do diálogo constante com as demandas advindas das questões sociais, ambientais, econômicas, regionais, climáticas dentre outras, que emergem nas relações sociais e na vida em sociedade.

É no contexto desse complexo universo de demandas que o aluno de arquitetura precisa processar as influências e informações recebidas, cabendo ao professor propiciar-Ihe a passagem da situação de aprendiz à de profissional independente e capaz de operar as transformações sociais necessárias. 


\section{Apresentando o guia de orientação técnica}

Denominado Guia para implantação de escritórios-piloto em cursos de Arquitetura e Urbanismo, trata-se de documento expositivo, argumentativo e de orientação técnica, elaborado com base em estudos bibliográficos e pesquisa empírica, que tem as finalidades de informar sobre fundamentos, princípios, objetivos e condições para a implantação de escritórios-piloto cujas finalidades são de propiciar aos alunos desses cursos uma formação profissional consistente, crítica e socialmente referenciada e de contribuir com o desenvolvimento local.

Em cursos de graduação, escritórios-piloto se referem a espaço de integração de atividades de ensino, pesquisa e extensão comprometidas com a melhoria da formação profissional dos estudantes e com a inserção social da instituição universitária nos esforços do desenvolvimento local.

Como espaço universitário, busca promover um contato mais estreito entre as vivências de sala de aula com as intervenções práticas desenvolvidas na execução de projetos civis em situações reais e concretas e também promove uma maior aproximação entre docentes e alunos.

É um recurso que contribui para o desenvolvimento local por meio da execução de projetos de pequenas reformas em atendimento a demandas construtivas locais de comunidades desprovidas de recursos para a contratação de profissionais arquitetos.

É uma estratégia não assistencialista, mas emancipadora de todos os que nela se engajam, pois vai além da prestação de serviços a comunidades na medida em que contribui para formar profissionais críticos e propositivos, produzir ou renovar os conhecimentos existentes e promover a valorização da instituição universitária no contexto da vida social.

Constitui-se, portanto, como objetivo geral do escritório-piloto, desenvolver ações integradas e integradoras de extensão, ensino-aprendizagem e pesquisa, que tenham como alvos a elaboração e execução de projetos construtivos de interesse social. São seus objetivos específicos: a) consolidar conhecimentos de diferentes áreas e a formação de arquitetos urbanistas; b) desenvolver estratégias metodológicas de aproximação com as comunidades público-alvo das suas ações; c) assessorar a população de baixa renda na capacitação para o desenvolvimento de projetos construtivos tendo em vista a captação de recursos em agências financiadoras; d) desenvolver projetos construtivos adaptados às realidades locais dessas comunidades; e) assessorar a população de baixa renda no processo de construção de suas moradias; f) estabelecer uma rede de intercâmbio envolvendo experiências acadêmicas semelhantes.

Para além do âmbito escolar e de formação profissional, esse Guia pode também ser do interesse de conselhos profissionais como o CREA e o CAU, sindicatos, organizações da sociedade civil de interesse público, organizações não-governamentais, órgãos públicos e empresas, que tenham o objetivo de promover o intercâmbio de conhecimentos e de inovações tecnológicas.

Os escritórios-piloto se oferecem como um importante veículo de extensão universitária, processo interdisciplinar, educativo, cultural, científico e político que promove a intera- 
ção transformadora entre as instituições de ensino superior e os outros setores da sociedade pautando-se pelo princípio da sua indissociabilidade em relação ao ensino e à pesquisa.

Como requisitos para implantar o escritório-piloto, em primeiro lugar, é necessário que a instituição universitária aprove a iniciativa e a institucionalize definindo-a como prática acadêmica com diretrizes, normas e procedimentos próprios; entendendo-a não como algo decorrente da ação individualizada de alguns poucos interessados, mas como atividade regular, integrada ao ensino e à pesquisa, dotada de recursos orçamentários.

Para tanto, o escritório-piloto deve contar com:

a) espaço físico e equipamentos;

b) equipe responsável formada por coordenador; professores que acompanhem os projetos; estagiários e, pelo menos, um funcionário administrativo;

c) plano e instrumentos de comunicação social para divulgar suas finalidades e atividades, especialmente nas comunidades localizadas na proximidade da instituição universitária e com o perfil socioeconômico previsto para atendimento;

d) política de relacionamento institucional com setores externos à instituição universitária com potencial e interesse em firmar parcerias destinadas à sustentação das atividades.

O modelo organizacional para o escritório-piloto precisa estar apoiado em estrutura simples, com a autonomia necessária ao controle das atividades desenvolvidas, requer coordenação com certo grau de centralização, sem, contudo, deixar de ser participativa e facilitadora da comunicação direta entre todos os participantes, garantindo facilidade de acesso e obtenção de informações e o desenvolvimento da cultura colaborativa e responsável.

O grupo de trabalho destinado à coordenação deve incluir professores e alunos, mas também funcionários administrativos e representantes de comunidades locais.

A boa condução da relação pedagógica envolvendo alunos, professores e instituição universitária e da relação entre essa e as comunidades atendidas é uma condição fundamental para o adequado funcionamento do escritório-piloto, que deverá ser embasado em normas consensuadas, objetivas, claras e de conhecimento amplo.

Quanto aos alunos participantes, eles deverão estar integrados com os compromissos e a realidade do escritório-piloto em face de suas responsabilidades e ética social.

É desejável a troca de experiências entre as equipes dos projetos e que essas experiências sejam devidamente sistematizadas tendo em vista a formação da memória coletiva do escritório-piloto.

Os horários de funcionamento do escritório-piloto deverão ser previstos de forma a contemplar efetivamente e com a agilidade adequada a demanda recebida e acordada com as comunidades. Com esse propósito também devem se mobilizar as equipes responsáveis pelos projetos.

Um dos critérios a serem adotados na seleção dos candidatos a estágio deverá ser a facilidade de interagir com a população local.

Reuniões periódicas e abertas a todos os participantes são fundamentais para assegurar a coesão grupal na realização das metas previstas e para que os fundamentos e princípios político-pedagógicos de materializem de fato.

$\mathrm{Na}$ implantação de escritórios-piloto, é importante considerar a possibilidade de surgimento de algumas dificuldades, tais como problemas com a falta de interesse da ins- 
tituição universitária, com a sustentabilidade financeira, a inexistência de organizações interessadas em firmar parcerias, a indisponibilidade de tempo por parte dos alunos e dos professores para os projetos, limitações dos espaços físicos, descumprimento das regras estabelecidas para seu funcionamento, a falta de manutenção ou obsolescência dos equipamentos, a possibilidade de descontinuidade dos trabalhos em períodos de férias escolares, e os desafios da construção da autonomia em relação às instâncias superiores das instituições universitárias.

$\mathrm{Na}$ busca da superação dos problemas que possam surgir na implantação e desenvolvimento dos escritórios-piloto, podem ser acionadas algumas estratégias e recursos tais como: reforçar a divulgação das finalidades e atividades do escritório-piloto junto às comunidades interna e externa às instituições universitárias; dedicar maior atenção às ações de conquista de parcerias e patrocinadores; incluir as atividades no escritório-piloto na matriz curricular do curso; destinar maior tempo à orientação dos alunos; prever formas de premiação dos alunos como incentivo à participação e melhorar a qualidade do planejamento, do acompanhamento e da avaliação das atividades.

\section{Considerações finais}

A consulta realizada a 70 alunos e 20 professores de dois cursos de Arquitetura e Urbanismo, repartidos igualmente por duas instituições de ensino, uma pública e outra particular, indicou que metade dos alunos disse ter algum ou nenhum conhecimento sobre experiências de escritório-piloto em cursos da área.

Em geral, as respostas tanto dos alunos quanto dos professores foram no sentido de considerar esse aparato pedagógico como uma importante ferramenta para a formação discente, pois contribui para o enriquecimento teórico, o desenvolvimento da prática profissional e a integração do curso com a população local. Os professores apontaram a questão da necessidade do desenvolvimento de inovações pedagógicas por meio da inserção social do aluno colocando-o em contato direto com a realidade do campo profissional para o qual está sendo formado.

Vale acrescentar que esta proposta deve ser considerada não apenas por cursos de Arquitetura e Urbanismo, mas também por associações, sindicatos, conselhos profissionais e outros espaços de formação profissional destinada à construção civil, pois sua concretização passa pelo entendimento amplo de sua importância pedagógica e social e pelo apoio que órgãos públicos e entidades da sociedade civil precisam lhe emprestar.

\section{Referências}

1.BRASIL. Presidência da República. Lei no 11.888, de 24 de dezembro de 2008. Assegura às famílias de baixa renda assistência técnica pública e gratuita para o projeto e a construção de habitação de interesse social e altera a Lei no 11.124, de 16 de junho 
de 2005. Disponível em: http://www.planalto.gov.br/ccivil_03/_Ato2007-2010/2008/ Lei/L11888.htm. Acesso em 30 jul. 2015.

2.ARCIPRESTE, Cláudia Maria. Entre o discurso e o fazer arquitetônico: Reflexões sobre o ensino de arquitetura e urbanismo e seus referenciais a partir do trabalho final de graduação. São Paulo, 2012. 287 p. Tese (Doutorado). - Universidade de São Paulo, São Paulo, 2012, p. 25.

3. PAVESI, Alessandra. A ambientalização da formação do arquiteto: o caso do Curso de Arquitetura e Urbanismo da Escola de Engenharia de São Carlos (CAU, EESC-USP). São Carlos: UFSCar, 2007. 199 f. Tese (Doutorado). - Universidade Federal de São Carlos, São Carlos, 2007, p.36.

4.SCHREGA, Antônio Carlos Espíndola. Conhecimento tácito e reflexão na ação: em busca de paradigmas emergentes no ensino de arquitetura e urbanismo na pontifícia universidade católica do Paraná. Curitiba, 2005. 76 p. Dissertação (Mestrado) - Pontifícia Universidade Católica do Paraná, 2005, p.6. 